\title{
Mini-Mental Parkinson: first validation study of a new bedside test constructed for Parkinson's disease
}

\author{
F. Mahieux ${ }^{1},{ }^{2}$, D. Michelet ${ }^{1}$, M.-J. Manifacier ${ }^{1}$, F. Boller ${ }^{2}$, J. Fermanian $^{3}$ and \\ A. Guillard ${ }^{1}$ \\ ${ }^{1}$ Service de Neurologie, Hôpital Tenon, Paris, ${ }^{2}$ INSERM, U 324, Paris and ${ }^{3}$ Département de \\ Statistique Médicale, Hôpital Necker, Paris, France \\ Correspondence to: F. Mahieux, Service de Neurologie, Hôpital Tenon, 4 rue de la Chine, \\ 75970 Paris Cedex, France
}

\begin{abstract}
We have developed a brief screening test aimed at identifying cognitive disorders in Parkinson's disease. The Mini-Mental Parkinson derives from the Mini-Mental State Examination of Folstein. It includes seven ordered subsections, with a total score of 32. A pilot study was conducted in $\mathbf{5 0}$ community-dwelling parkinsonian patients, in order to establish its metrological qualities. Comparisons were made with a neuropsychological battery including several tests widely used in the assessment of specific cognitive disorders in Parkinson's disease. The correlations between the Mini-Mental Parkinson and each component of this battery were substantial, especially for the performance subtests of the WAIS-R $(r=0.62$ to 0.72$)$, the Stroop test $(r=0.65)$ the 15-objects test $(r=0.64)$, the word fluency $(r=0.63)$ and the Odd Man Out test $(r=0.61)$. The validity of each subtest of the Mini-Mental Parkinson was adequate except for one, based on a word choice, which requires a modification in French before definitive use. The test-retest reliability was high $(r=0.84)$. There was a significant difference in the mean scores in cases with confusional event (22.4), even without current signs of dementia, compared with patients with no such history (27.2). In conclusion, this brief test is suitable for assessment of parkinsonian patients.
\end{abstract}

Keywords: Cognitive disorders - Dementia - Neuropsychological assessment - Parkinson's disease - screening test

\section{INTRODUCTION}

Cognitive disorders in Parkinson's disease (PD) have been studied extensively in recent years (for reviews, see Brown and Marsden, 1991; Guillard et al., 1991; Dubois et al., 1991). Attempts to define them more precisely have led to the development of numerous tests but there have been growing discrepancies in experimental design and methods. The increasing complexity and duration of neuropsychological assessments are two of the main barriers to establishing the prevalence, incidence and progression of specific cognitive disorders in large populations of PD patients (Biggins et al., 1992).

In Alzheimer's disease and related disorders, bedside tests such as the Mini-Mental State (MMS) (Folstein et al., 1975) and Information Memory Concentration test (Blessed et al., 1968) have been adopted, making it possible to compare data from different studies, to perform long-term longitudinal studies on large populations and to screen well-defined population samples for therapeutic trials. These short tests are especially helpful when patients cannot

(C) 1995 Rapid Communications of Oxford Ltd co-operate in longer and more comprehensive assessments. As they stand, these standard batteries are not fully suitable for evaluating cognitive status in PD. Indeed, they have been developed with the explicit aim of screening for dementia of Alzheimer's type (DAT) according to its pattern of cognitive deficits, with aphasia and memory disorders as prominent features; their cut-off scores have thus been validated in this setting. However, differences between the cognitive disorders in PD and DAT are now well established (Lavernhe et al., 1989; Sullivan et al., 1989; Dubois et al., 1991). In particular there are two steps for cognitive disorders in PD: first, early "subtle" cognitive troubles, qualitatively and quantitatively quite different from DAT impairment; second, it may inconstantly appear dementia.

A suitable tool for screening specific disorders of PD needs to be sensitive, but avoid a ceiling effect since the earlier troubles, and to save some sensitivity for possible dementia. These criteria are not fulfilled 
TABLE I. Characteristics of the patients

\begin{tabular}{llrc}
\hline & Mean & S.D. & Range \\
\hline Age (years) & 66.5 & 8.3 & $46-83$ \\
Gender (M: $F$ ) & $30: 20$ & & \\
Education (years) & 11.3 & 4.3 & $5-19$ \\
Duration of PD (years) & 8.6 & 5.9 & $0.5-25$ \\
Hoehn \& Yahr stage & 1.7 & 1.2 & $0-5$ \\
UPDRS scores & & & \\
$\quad$ I (cognitive state) & 2.5 & 2.3 & $0-10$ \\
II on (activities of daily living) & 8.2 & 5.4 & $0-21$ \\
$\quad$ II off ( $n=28$ ) & 19.0 & 8.4 & $7-42$ \\
III (motor examination) & 17.6 & 15.9 & $2-66$ \\
Depression score (CES-D) & 18.6 & 9.3 & $2-39$ \\
Anxiety score (Zung) & 38.7 & 8.3 & $22-59$ \\
& & & \\
\hline
\end{tabular}

TABLE II. Mini-Mental Parkinson subsections and scores

\begin{tabular}{lr}
\hline Orientation & 10 \\
Visual registration & 3 \\
Attention/mental control & 5 \\
Two-set verbal fluency & 3 \\
Visual recall & 4 \\
Shifting & 4 \\
Concept processing & 3 \\
Maximal total score & 32 \\
\hline
\end{tabular}

by current bedside tests. Given that need, we have developed a short bedside test, the Mini-Mental Parkinson (MMP), designed specifically to assess the cognitive disorders in PD, and aimed at identifying those patients requiring in-depth assessment. Like the MMS, from which it derives, it consists of serial subsections evaluating different cognitive domains. We present the results of a pilot study designed to validate the MMP.

\section{METHODS}

\section{Subjects}

We studied 50 PD patients in the neurological ward and out-patient clinic of Tenon Hospital, Paris, France. All gave their written informed consent to the study and computer analysis of the recorded data. None had associated neurological disease. Each patient was rated independently by a senior neurologist (F.M.) using the Unified Parkinson's Disease Rating Scale (UPDRS; Stern, 1988) and the Hoehn \& Yahr scale (Hoehn and Yahr, 1967). The motor examination (UPDRS-III) score matched the state of the patients at the time of the MMP to within about 10 min, whether they were in the "on" or the "off" state. The Center for Epidemiologic Studies-Depres- sion (CES-D; Fuhrer and Rouillon, 1989) and Zung anxiety (Zung, 1971) self-rating scales (French translation) were filled in by the patients. According to French cut-off scores (Fuhrer and Rouillon, 1989) 15 patients were considered as slightly depressed; none fulfilled DSM-III-R criteria for major depressive episodes. All the patients were taking anti-parkinsonian medication (dopaminergics in 43 cases and a combination of dopaminergics and anticholinergics in seven cases). The patients' main characteristics are presented in Table I.

\section{Materials}

The MMP is derived from the Folstein MMS (Folstein et al., 1975). It includes seven ordered subsections, each scored as shown in Table II. The reasons for the modifications are as follows. The modification of the orientation subtest derives from the known early difficulties for time estimation due to frontal-related disorders (Milner and Petridès, 1984) and PD (Pastor et al., 1992). Memory disturbances in PD appear at a late stage and seem to be much more complex than can be revealed by three word learning and recall (Taylor et al., 1986; Sagar et al., 1988; Raoul et al., 1992). Thus, the MMP memory subsection was constructed to avoid simple categorizations and requires internal cues (Brown and Marsden, 1991), mental imagery and visuospatial abilities. The question of the initial order of presentation was added because of the known sequencing deficit in PD (Sagar et al., 1988; Cooper et al., 1993). The subsection "Calculation and mental control", presumed to be sensitive to attention and frontal abilities, was unchanged. Language disorders are slight in early.PD and limited to difficulties in fluency tasks (Matison et al., 1982; Lees and Smith, 1983). The language subsection of the MMS was therefore replaced by a single task (two-set fluency) designed to combine the only well-known language disorder in PD with a shifting process (Downes et al., 1993). The design copy task of the MMS was not used, because it requires motor abilities and thus leads to a strong potential bias in PD, a disease with predominant motor symptoms. A specific shifting task was derived from the Odd Man Out paradigm (Flowers and Robertson, 1985), given the difficulties for parkinsonian patients to generate set-shifting behaviour (Lees and Smith, 1983; Taylor et al., 1986). The "concept processing" subsection was designed to explore cognitive processes, involved in similarity tasks, that are thought to be sensitive to dementing processes. Choice was used rather than free explanation in order to avoid scoring discrepancies.

The test is thus presented as follows. Orientation is 

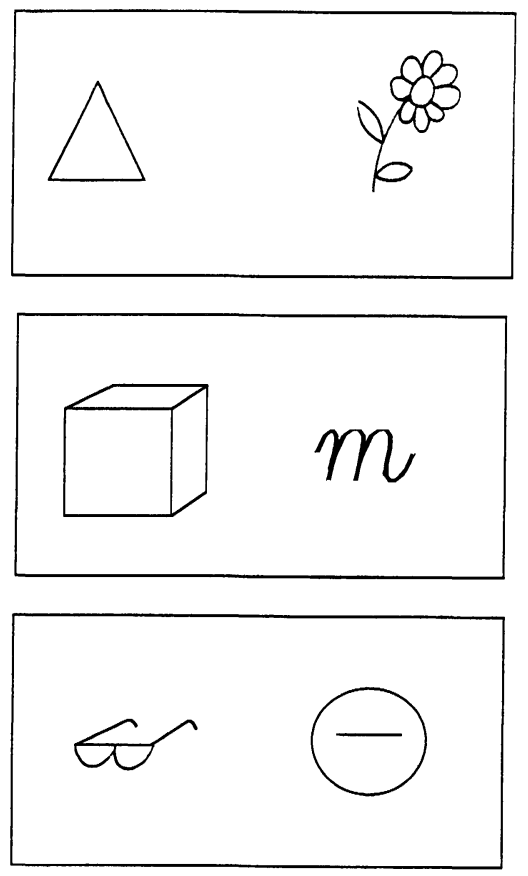

(a)
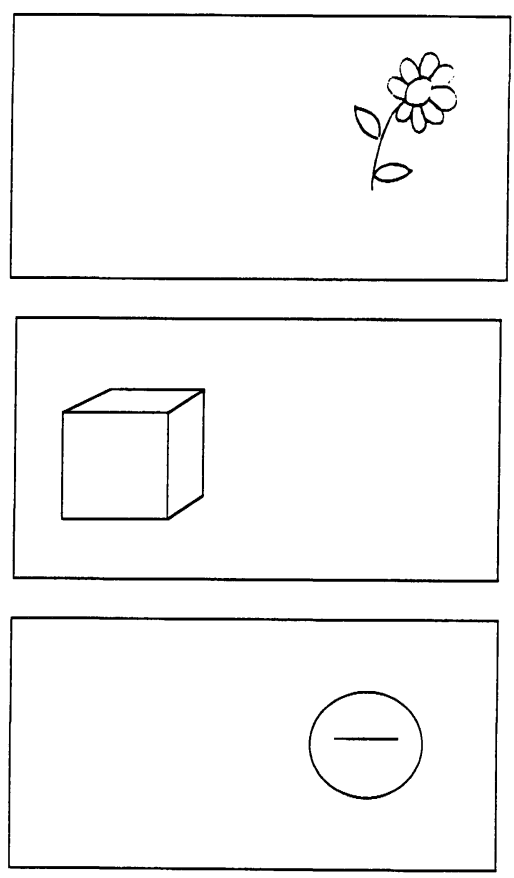

(b)

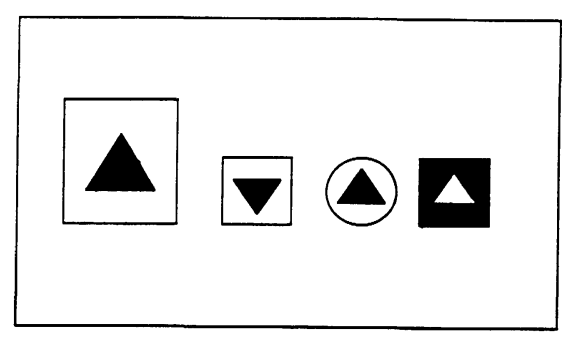

(c)

FIG. 1 (a) Visual registration cards.

(b) Visual recall cards. (c) Shifting cards.

constituted by the 10 classic items of the MMS (five temporal and five spatial) except for the "season" item, which is replaced by the question "What time is it?", with a 1 h tolerance each way. Visual registration is based on three cards (Fig. 1a), each representing two totally unrelated pictures: a living creature plus a purely geometric shape, a three-dimensional design plus a letter, and a symbol plus an everyday object. The three cards are presented in sequence once the nature of the task has been explained. The score is based on the number of presentations necessary for immediate recall of the six images. Precise instructions for assessment and scoring are given in the appendix. Attention and mental control are explored according to the classical Folstein design (serial sevens and backward spelling, scored on the best of the two). The two-set verbal fluency task consists of giving three names of animals beginning with the same letter. The visual recall test consists of the same three cards used in the visual registration subsection, but each with one image missing (Fig. 1b). They are presented simultaneously, and the task is to remember the nature and, above all, the position of the missing pictures and the initial order of presentation. The mental shifting subsection consists of a card with four pictures (Fig. 1c). The task is to indicate which of the four is different from the other three. The patient is then asked to find another image which can also be the odd one out and so on, until he or she finds the four features singling out each of the four pictures (color, shape, orientation and size). Concept processing consists of three groups of three words. In each group, two words belong to the same semantic category (fruit, clothes, furniture) while the third is unrelated. The task is to indicate which two words of each triplet are the most closely related.

A retest with another rater was performed, although parallel forms were only available for the "concept processing" subsection. However, instructions were standardized and typed (see Appendix).

\section{Validation battery}

We chose a comprehensive neuropsychological examination rather to a composite instrument, such as the Mattis dementia rating scale (Mattis, 1976), to allow comparisons between precise cognitive functions (defined by the performances at specific tasks) and the MMP and its subsections.

The comprehensive assessment selected for the validation included the following tests. (1) A shortened form of the WAIS-R (Wechsler, 1981) for which verbal IQs were pro-rated from the vocabulary, comprehension, arithmetic and similarities subtests and performance IQs were pro-rated from the picture completion, block design and picture arrangement subtests. Raw scores for all the subtests were used for the statistical analysis, together with the Verbal and Performance IQs. (2) A shortened form of the Wechsler Memory Scale (Wechsler, 1945), including the digit span and the three subtests involving secondary memory (i.e. logical memory, visual memory and 
associate learning). (3) Frontal-sensitive tasks included verbal fluency (letter $M$, and animals), the words (A), colours (B) and coloured-word (C) tasks of the Stroop test (Stroop, 1935), each limited to $45 \mathrm{~s}$, the WCST according to Nelson's short design (Nelson, 1976), the Odd Man Out test (only four successive trials; Flowers and Robertson, 1985) and the 15-object test whose final score was the number of objects identified in the $120 \mathrm{~s}$ allotted (Pillon et al., 1989). The patients also underwent the Benton Line Orientation test (Benton et al., 1978) and the MMS examination (Folstein et al., 1975). The neuropsychological battery as well as MMP retest were performed by a neuropsychologist blind for the MMP test result.

\section{Statistical analysis}

The quantitative variables were described using the usual parameters: means, (S.D.) and histograms. Comparison of means of two independent groups was done using Student's $t$-test, and Mann-Whitney $\mathrm{U}$ test when the assumptions of the $t$-test were seriously violated. The level of significance was $p<0.05$. The association between two quantitative variables was described by the Pearson's product-moment correlation coefficient $r$, and by Spearman's rank correlation when the distribution was skewed.

Construct validity of the MMP. The coefficient $r$ was calculated between the MMP total score and each test of the validation battery (Parrott, 1991a). Moreover, the means of the scores obtained by each patient with and without a history of confusion or hallucinosis were compared using the $t$-test for the MMP total score and $\mathrm{U}$ test for its subsections, assuming these events are predictive for the development of dementia (Guillard et al., 1991).

Content validity of the MMP. The Spearman's rank coefficient was calculated between each subsection of the MMP and each test of the validation battery.

Factor analysis of the MMP. The initial factor solution was obtained from the principal components method and a varimax rotation was performed.

Inter-rater reliability. The intra-class correlation coefficient was used (Parrott, 1991b; Bartko, 1966).

All the analyses were done using "Statistix" software (Analytical Software Inc.).

\section{RESULTS}

The mean MMP score for the 50 patients was 26.3
(S.D. = 3.9), with a range of 16-31. Figure 2 shows the score distribution histogram, as well as that for the MMS scores.

\section{Construct validity}

The total score of the MMP was significantly correlated with all the tests in the validation battery. The results of the correlation analyses ( $r$ coefficient and $p$ value) and the raw scores for all tests are summarized in Table III.

There was no significant correlation between the MMP and age $(r=-0.13)$ or the anxiety scores $(r=-0.21)$. Educational level $(r=0.32)$ and the CES-D $(r=-0.29)$ and UPDRS-I scores $(r=-$ $0.35)$ correlated weakly with the MMP $(p<0.05)$. The UPDRS-I scores correlated far better with the CES-D $(r=0.54)$ and anxiety scores $(r=0.52$; $p<0.001)$. Seven patients were treated with anticholinergics. There were no substantial changes in the results with exclusion of these patients.

Nine patients had a history of confusion or hallucinosis and a significantly lower mean MMP total score than the 41 other patients (Student's $t$-test; Table IV). Orientation alone, shifting and the two memory subsections were the most different subsections in the two groups.

We also carried out the same correlation analyses
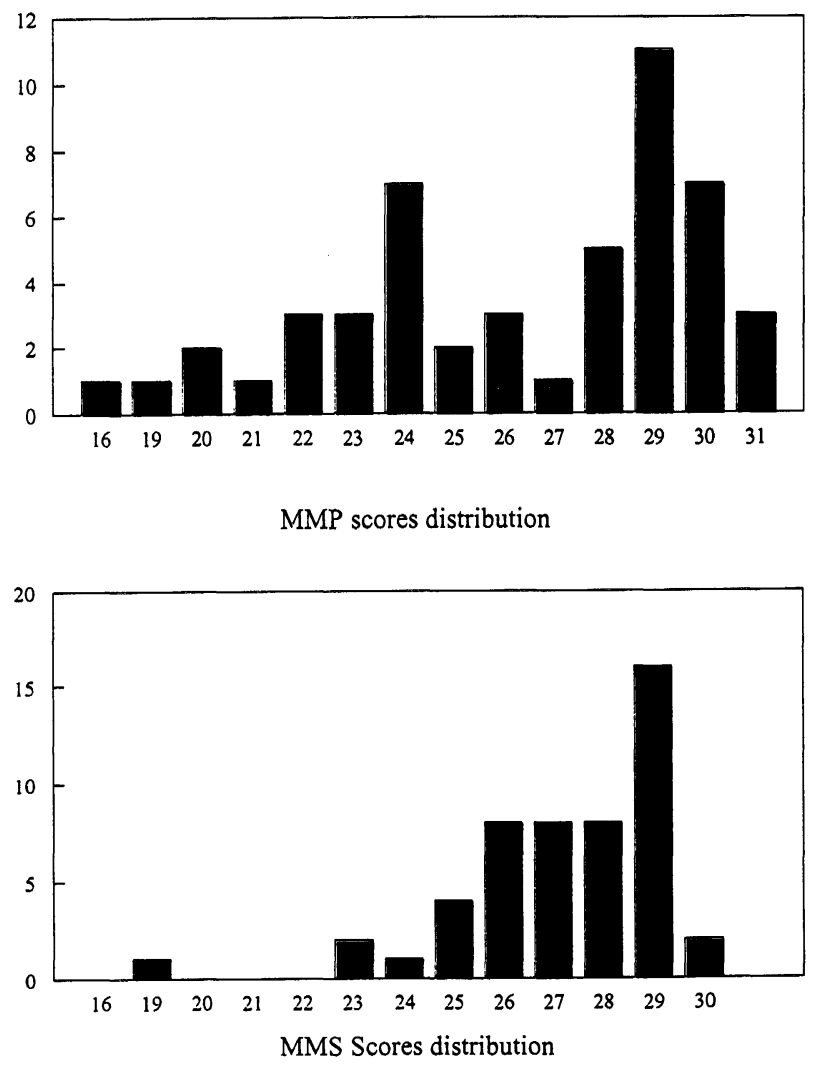

FIG. 2. Histograms of the scores of the MMP and MMS.

18 Behavioural Neurology . Vol 8.1995 
TABLE III. Construct validity. Mean raw scores of each test of the validation battery with corresponding Pearson's correlation coefficients $(r)$ with MMP and their level of significancy $(p)$ and $r$ correlation coefficients with MMS

\begin{tabular}{lcrrr}
\hline Variable & Raw scores & $r$ & $p$ & MMS \\
& Mean (S.D.) & & & $r$ \\
\hline Performance IQ & $86.5(19.5)$ & 0.72 & 0.001 & 0.52 \\
Blocks & $15.7(10.5)$ & 0.71 & 0.001 & 0.55 \\
Completion & $9.4(5.2)$ & 0.65 & 0.001 & 0.53 \\
Stroop C & $24.2(12.0)$ & 0.65 & 0.001 & 0.50 \\
15 Objects (N) & $11.4(3.0)$ & 0.64 & 0.001 & 0.45 \\
Fluency (letter) & $9.2(5.4)$ & 0.63 & 0.001 & 0.44 \\
WMS-Visual & $7.3(3.9)$ & 0.63 & 0.001 & 0.61 \\
Verbal IQ & $97.7(17.2)$ & 0.62 & 0.001 & 0.37 \\
Arrangement & $5.4(4.4)$ & 0.62 & 0.001 & 0.51 \\
Odd Man Out & $26.1(8.0)$ & 0.61 & 0.001 & 0.49 \\
Benton & $22.5(8.1)$ & 0.61 & 0.001 & 0.54 \\
Similarities & $14.0(7.3)$ & 0.60 & 0.001 & 0.32 \\
WMS-Associates & $13.7(4.0)$ & 0.60 & 0.001 & 0.39 \\
Arithmetic & $9.8(4.4)$ & 0.59 & 0.001 & 0.48 \\
Fluency (animals) & $16.0(6.1)$ & 0.55 & 0.001 & 0.37 \\
Comprehension & $17.3(6.2)$ & 0.54 & 0.001 & 0.41 \\
WCST (series) & $3.7(2.2)$ & 0.52 & 0.001 & 0.37 \\
WMS-Logical & $7.8(3.3)$ & 0.48 & 0.001 & 0.34 \\
WCST perseverations & $7.8(7.7)$ & -0.44 & 0.001 & -0.27 \\
Vocabulary & $41.0(15.5)$ & 0.43 & 0.01 & 0.29 \\
WCST-errors & $15.7(10.6)$ & -0.42 & 0.01 & -0.17 \\
WMS-Span & $9.2(1.9)$ & 0.38 & 0.01 & 0.43 \\
\hline
\end{tabular}

TABLE IV. Construct validity. Comparison of MMP and subsection scores according to history of confusion/hallucinosis with level of significancy $(p)$ for Student's $t$-test (for MMP total score) and Mann-Witney $U$ test (for subsections). Values are expressed as means (S.D.)

\begin{tabular}{lrrr}
\hline & $\begin{array}{c}\text { No } \\
\text { confusion } \\
(n=41)\end{array}$ & $\begin{array}{c}\text { Confusion/ } \\
\text { hallucinosis } \\
(n=9)\end{array}$ & $p$ \\
\hline MMP & $27.2(3.1)$ & $22.4(3.2)$ & $<0.01$ \\
Orientation & $9.5(0.8)$ & $8.7(0.7)$ & $<0.03$ \\
Registration & $1.6(1.1)$ & $0.7(0.9)$ & $<0.05$ \\
Attention & $4.8(0.5)$ & $4.6(0.7)$ & N.S. \\
Two-set fluency & $2.7(0.6)$ & $2.4(0.8)$ & N.S. \\
Visual recall & $2.9(1.3)$ & $1.4(1.1)$ & $<0.01$ \\
Shifting & $3.1(1.0)$ & $2.1(1.1)$ & $<0.02$ \\
Concept processing & $2.7(0.5)$ & $2.3(0.7)$ & N.S. \\
\hline
\end{tabular}

between the MMS and each test of the battery. The $r$ correlation coefficients are summarized in Table III.

\section{Content validity}

Correlation coefficients of each subsection of the MMP with each test of the neuropsychological battery (Table V) showed that: (1) orientation correlated poorly with only two tasks, including WMS associate learning; (2) visual registration correlated with all the memory tests (visual: $r=0.40$; associates: $r=0.36$; logical: $r=0.35$ ) and with visuospatial and interference control tasks; (3) the "attention and mental control" (backward spelling) subsection correlated with the Stroop C, Odd Man Out, fluency and Benton Line Orientation tests but not with span; (4) the fluency subsection correlated well with all the verbal items; (5) visual recall correlated with all the tests except vocabulary and span; the best correlations were with visuospatial skills and the WMS visual $(r=0.50)$; (6) the "shifting" subsection correlated with all the tests except span; the best correlations were with visuospatial tasks, Odd Man Out $(r=0.52)$ and WCST $(r=0.41)$; (7) the "concept processing" subsection did not correlate with any verbal, set-shifting or memory subtest. The principal components analysis after a varimax rotation showed four factors explaining $77.9 \%$ of the variance (Table VI). These loadings show that the factors could be interpreted as follows: the first factor $(33.3 \%)$ as visuospatial cognitive processes and reasoning; the second (18.4\%) as the "concept processing" alone; the third factor (14.4\%) as verbal abilities given that the score for the attention subsection was, in fact, always that for backward spelling; and the fourth factor $(11.8 \%)$ to orientation. 
TABLE V. Content validity. Correlation coefficients of each subsection of the MMP with the validation battery (Spearman's rank coefficient): the highest (statistically significant) coefficients

\begin{tabular}{|c|c|c|c|c|}
\hline \multirow[t]{2}{*}{ MMP } & \multicolumn{4}{|c|}{ Validation battery } \\
\hline & $\begin{array}{l}\text { Performance and } \\
\text { visuospatial tasks }\end{array}$ & Memory tasks & Set-shifting tasks & Verbal tasks \\
\hline Orientation & & $\begin{array}{l}\text { Associates } \\
\text { learning (0.29) }\end{array}$ & Stroop C (0.33) & \\
\hline Registration & Blocks $(0.50)$ & & Stroop C (0.52) & $\begin{array}{c}\text { Arithmetic }(0.53) \text { and } \\
\text { Similarities }\end{array}$ \\
\hline Attention & Benton lines $(0.31)$ & & $\begin{array}{l}\text { Odd Man Out (0.37) } \\
\text { and Stroop C (0.34) }\end{array}$ & Fluency letter $(0.36)$ \\
\hline Two-set fluency & Arrangement (0.44) & & Stroop C (0.37) & $\begin{array}{c}\text { Vocabulary }(0.47) \\
\text { and Fluency letter } \\
(0.40)\end{array}$ \\
\hline Visual recall & $\begin{array}{l}\text { 15-objects }(0.56) \text { and } \\
\text { Blocks }(0.54)\end{array}$ & $\begin{array}{l}\text { Visual memory } \\
(0.50)\end{array}$ & & $\begin{array}{c}\text { Fluency letter } \\
(0.54)\end{array}$ \\
\hline Shifting & $\begin{array}{l}\text { Blocks }(0.74) \text { and } \\
15 \text { Objects }(0.61)\end{array}$ & $\begin{array}{c}\text { Visual memory } \\
(0.57)\end{array}$ & Stroop C (0.58) & Similarities $(0.57)$ \\
\hline Concept processing & $\begin{array}{l}\text { PIQ (0.38) and } \\
\text { Completion (0.33) }\end{array}$ & & & \\
\hline
\end{tabular}

TABLE VI. Factors loading for each variable in the factor analysis (orthogonal solution, varimax rotation). Vertical lines indicates large loadings

\begin{tabular}{|c|c|c|c|c|}
\hline & $\begin{array}{c}\text { Factor } \\
1\end{array}$ & $\begin{array}{c}\text { Factor } \\
\text { II }\end{array}$ & $\begin{array}{c}\text { Factor } \\
\text { III }\end{array}$ & $\begin{array}{c}\text { Factor } \\
\text { IV }\end{array}$ \\
\hline V. Registration & 0.85 & -0.19 & 0.11 & 0.04 \\
\hline Visual recall & 0.73 & 0.11 & 0.10 & 0.40 \\
\hline Shifting & 0.71 & 0.39 & 0.19 & -0.11 \\
\hline $\begin{array}{l}\text { Concept } \\
\text { processing }\end{array}$ & 0.3 & 0.92 & 0.05 & 0.04 \\
\hline Attention & 0.15 & -0.13 & 0.84 & 0.07 \\
\hline Two-set fluency & 0.12 & 0.27 & 0.79 & 0.00 \\
\hline Orientation & 0.10 & -0.07 & 0.04 & 0.96 \\
\hline $\begin{array}{l}\text { Percentage of } \\
\text { the variance } \\
\text { explained by } \\
\text { the factor }\end{array}$ & $33.3 \%$ & $18.4 \%$ & $14.4 \%$ & $11.8 \%$ \\
\hline
\end{tabular}

\section{Reliability}

The inter-rater reliability assessment showed a highly significant intra-class correlation $(0.84 ; p<0.001)$ for the MMP total score.

\section{DISCUSSION}

The MMP total score correlated with each component of the neuropsychological battery. The best correlations concerned the WAIS-R performance subtests, Odd Man Out, Stroop, WCST (series), fluency, 15 objects and Benton Line Orientation tests, which are the most strongly involved in PD cognitive disorders (Lees and Smith, 1983; Sullivan et al., 1989). All these correlations fell into the "very good"
$(0.61 \leqslant r \leqslant 0.80)$ range (Feinstein, 1987); others were only "satisfactory" $(0.41 \leqslant r \leqslant 0.60)$, but they were the least specific for PD. In particular, the poor correlation with the span and vocabulary tests is consistent with the long-term stability of these parameters in PD (Sullivan et al., 1989; Brown and Marsden, 1991). The increased dispersion of MMP total scores versus MMS total scores (Fig. 2) provides strong additional argument for a better sensitivity of the MMP to earlier specific disorders in PD. Moreover the correlations of the MMS with the tasks most sensitive to PD-specific disorders appear far weaker than that of the MMP. The spread of the correlations and the four factors, in the factor analysis of the MMP, were in keeping with a composite instrument, an important property given the probable multidimensional nature of cognitive disorders in PD. Thus, the global score of the MMP emerged as a valuable predictor of the results of a wide screening battery for cognitive disorders in PD. The test-retest correlation was fully satisfactory.

With regard to the content validity study, the orientation subsection was the same as in the MMS, except for the replacement of one item. The correlation analysis failed to show strong links between orientation and the components of our battery. However, the orientation subtest of other tools such as WMS--revised (Wechsler, 1987) is not correlated with other subtests either. Orientation could be a relatively specific cognitive function with a poor overlap with other tasks. With regard to the visual memory subsections, Table IV shows that they correlated better with visuospatial tasks and that involving attention and mental manipulation of data (Brown 
and Marsden, 1991) than with pure memory tasks. However, the fact that some constructional abilities are a necessary condition for this task meets our aims for these subsections. There was no correlation of the "calculation and mental control" subsection with the span, usually considered as reflecting attention. However, there were fair correlations with three tasks requiring high levels of vigilance and control. The correlation of the verbal fluency subsection with verbal items was adequate. The correlations of our "shifting" subsection with all the visuospatial skills and the two classical set-shifting tasks seemed adequate. The concept processing subsection did not correlate with any verbal reasoning task, and constitutes a separate factor in factor analysis. Recognizing this dimension as important, we shall analyse it more accurately in the future. Future work will also be devoted to the study of comparison groups.

In conclusion, the MMP fulfilled most of our expectations; in particular, it provided an adequate estimate of the results of most tests used in the cognitive follow-up of PD patients.

\section{Acknowledgements}

We thank Mr D. Young for revision of the English, and Dr M. Panisset for useful suggestions. This work was supported by a grant from Produits Roche France (1990 Roche Prize).

\section{REFERENCES}

Bartko JJ (1966) The intra class correlation coefficient as a measure of reliability. Psychological Reports, 19, 3-11.

Benton AC, Varney NR and Hamsher K de S (1978) Visuo-spatial judgement. A clinical test. Archives of Neurology, 35, 364-367.

Biggins CA, Boyd JL, Harrop FM, Madeley P, Mindham RHS, Randall JI and Spokes EGS (1992) A controlled longitudinal study of dementia in Parkinson's disease. Journal of Neurology, Neurosurgery and Psychiatry, 55, 566-57.

Blessed G, Tomlinson BE and Roth M (1968) The association between quantitative measures of dementia and of senile changes in the grey matter of elderly subjects. British Journal of Psychiatry, 114, 797-811.

Brown RG and Marsden CD (1991) Cognitive function in Parkinson's disease: from description to theory. Trends in Neurosciences, 13, 21-29.

Cooper JA, Sagar HJ and Sullivan EV (1993) Short-term memory and temporal ordering in early Parkinson's disease: effect of disease chronicity and medication. Neuropsychologia, 31, 933-949.

Downes JJ, Sharp HM, Costall BM, Sagar HJ and Howe J (1993) Alternating fluency in Parkinson's disease. Brain, 116, 887-902.

Dubois B, Boller F, Pillon B and Agid Y (1991) Cognitive deficits in Parkinson's disease. In: Handbook of Neuropsychology, Vol. 5, (Eds F Boller and J Grafman), pp. 195240. Elsevier, Amsterdam.
Feinstein AR (1987) Clinimetrics. Yale University Press, New Haven, CN.

Flowers KA and Robertson C (1985) The effect of Parkinson's Disease on the ability to maintain a mental set. Journal of Neurosurgery and Psychiatry, 48, 517-529.

Folstein SE, Folstein MF and McHugh PR (1975) "MiniMental State": a practical method for grading the cognitive state of patients for the clinician. Journal of Psychiatric Research, 12, 189-198.

Fuhrer R and Rouillon F (1989) La version francaise de l'échelle CES-D (Center for Epidemiologic Studies-Depression scale). Description et traduction de l'échelle d'auto-évaluation. Psychiatrie et Psychobiologie, 4, 163166.

Guillard A, Fénelon G and Mahieux F (1991) Les altérations cognitives au cours de la maladie de Parkinson. Revue Neurologique (Paris), 147, 337-355.

Hoehn MM and Yahr MD (1967) Parkinsonism: onset, progression and mortality. Neurology, 17, 427-442.

Lavernhe G, Pollak P, Brenier F, Gaio JM, Hommel M, Pellat J and Perret J (1989). Maladie d'Alzheimer et maladie de Parkinson. Differentiation neuropsychologique. Revue Neurologique, 145, 24-30.

Lees AJ and Smith E (1983) Cognitive deficits in the early stages of Parkinson's disease. Brain, 106, 257-270.

Matison R, Mayeux R, Rosen J and Fahn S (1982) "Tipof-the-tongue" phenomenon in Parkinson's Disease. Neurology, 32, 567-570.

Mattis S (1976) Mental status examination for organic mental syndrome in the elderly patients. In: Geriatric Psychiatry, (Eds L Bellak and TB Karasu). Grune \& Stratton, New York.

Milner B and Petridès M (1984) Behavioural effects of frontal-lobe lesions in man. Trendsin Neuroscience 7, 403-407.

Nelson HE (1976) A modified card sorting test sensitive to frontal lobe defects. Cortex, 12, 313-324.

Parrott A (1991a) Performance tests in human psychopharmacology (1): test reliability and standardization. Human Psychopharmacology, 6, 1-9.

Parrott A (1991b) Performance tests in human psychopharmacology (2): content validity, criterion validity and face validity. Human Psychopharmacology, 6, 91-98.

Pastor MA, Artieda J, Jahanshahi M and Obeso JA (1992) Time estimation and reproduction is abnormal in Parkinson's Disease. Brain, 115, 211-225.

Pillon B, Dubois B, Bonnet AM et al., (1989) Cognitive slowing in Parkinson's disease fails to respond to levodopa treatment: the 15-objects test. Neurology, 39, 762768.

Raoul P, Lieury A, Decombe R, Chauvel P and Alain H (1992) Déficit mnésique au cours de la Maladie de Parkinson. Vieillissement accéléré des processus de rappel. Presse Médicale, 21, 69-73.

Sagar HJ, Cohen NJ, Sullivan EV, Corkin S and Growdon JH (1988) Remote memory function in Alzheimer's disease and Parkinson's Disease. Brain, 111, 185-206.

Stern MB (1988) The clinical characteristics of Parkinson's disease and parkinsonian syndromes: diagnosis and assessment. In: The Comprehensive Management of Parkinson's Disease (Eds MB Stern and HI Hurtig), pp. 3-50. PMA, New York.

Stroop J (1935) Studies of interferences in serial verbal reactions. Journal of Experimental Psychology, 18, 643662. 
Sullivan EV, Sagar HJ, Gabrieli JDE, Corkin S and Growdon JH (1989) Different cognitive profile on standard behavioral tests in Parkinson's disease and Alzheimer's disease. Journal of Clinical and Experimental Neuropsychology, 11, 799-820.

Taylor AE, Saint Cyr JA and Lang AE (1986) Frontal lobe dysfunction in Parkinson's disease. Brain, 109, 845-883.

Wechsler D (1945) A standardised memory scale for clinical use. Journal of Psychology, 19, 87-95.

Wechsler D (1981) The Wechsler Adult Intelligence ScaleRevised, Psychological Corporation, San Antonio.

Wechsler D (1987) Wechsler Memory Scale-Revised Manual, Psychological Corporation, New York.

Zung WWK (1971) A rating instrument for anxiety disorders. Psychosomatics, 12, 371-379.

(Received 1 March 1994; accepted as revised 1 December 1994)

\section{APPENDIX: INSTRUCTION FOR THE ADMINISTRATION OF THE MINI-MENTAL PARKINSON EXAMINATION}

\section{Orientation}

1. Ask for the date, then ask specifically for parts omitted and say"can you also tell me, without looking at your watch, what time it is?" One point for each correct element (day, date, month, year, hour).

2. Ask in turn "can you tell me where we are?" One point for each correct answer (five spatial items according to local particularities).

\section{Registration}

"Now I shall test your memory. I shall show you picture cards and I want you to tell me what you see. Then I shall hide the cards and ask you to recall them." Show the three cards, in order; 3 points if the patient remembers the images, whatever the order of recall. If he or she can't recall all six, show the cards again in the same order with the same instructions. Full recall (whatever the order) at the second attempt scores 2 points. If necessary, make a third presentation; 1 point if the third recall is correct.

\section{Attention and mental control}

Ask the patient to count backwards from 100 in five 7-point steps. Then, ask him or her to spell the word "world" backwards (all patients).

\section{Two-set fluency}

Ask for the names of three animals beginning with the same letter (in French, L); 30 s. are allotted.

\section{Recall}

Place the three cards simultaneously in a triangle on the table: "Here are the cards you've seen, but one image is missing from each, can you tell me which it is?" One point per correct position recalled. "And can you tell me what order they were in?" 1 point.

\section{Shifting}

"Here are four pictures; oan you tell me if one of them is different from the other three?" Then ask why. If the answer is correct, ask for another, with the same instructions. Stop when the four characteristics have been found, when the patient fails to find another one, or when a previously found characteristic is repeated.

\section{Concept processing}

"I shall say three words, and I want you to tell me which two are most closely related." In French: train, bag, boat; then hat, glove, rakes; then orange, carrot, grapes; 1 point per correct association. 


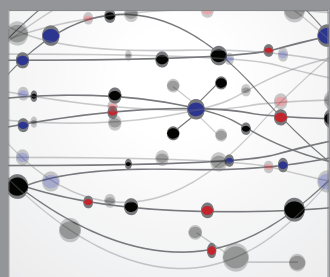

The Scientific World Journal
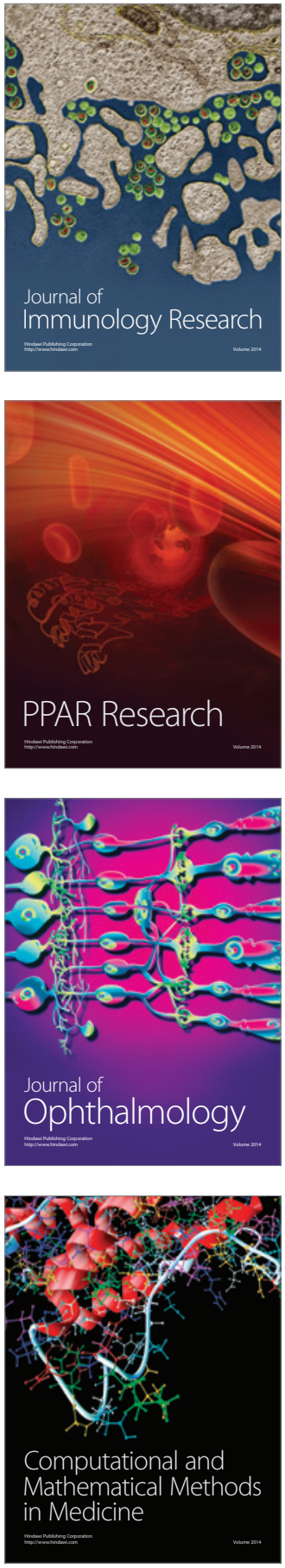

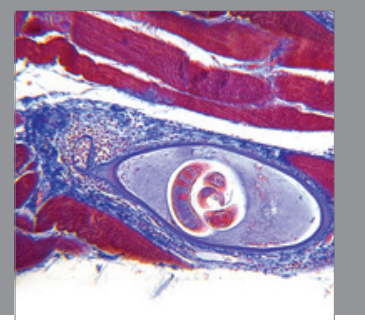

Gastroenterology

Research and Practice
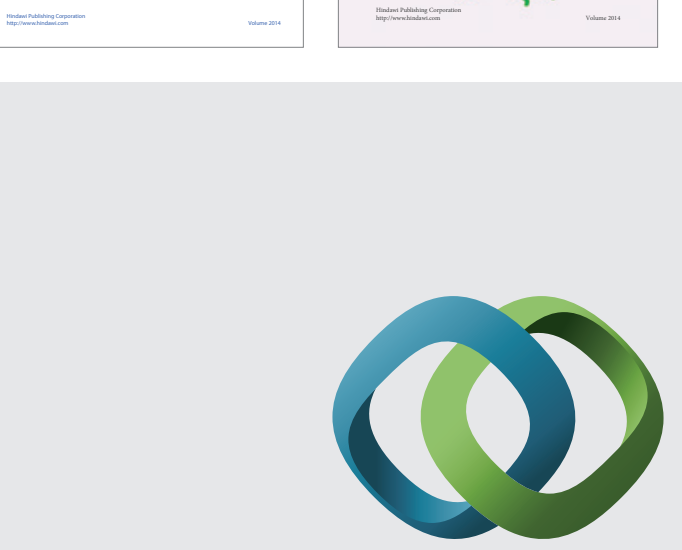

\section{Hindawi}

Submit your manuscripts at

http://www.hindawi.com
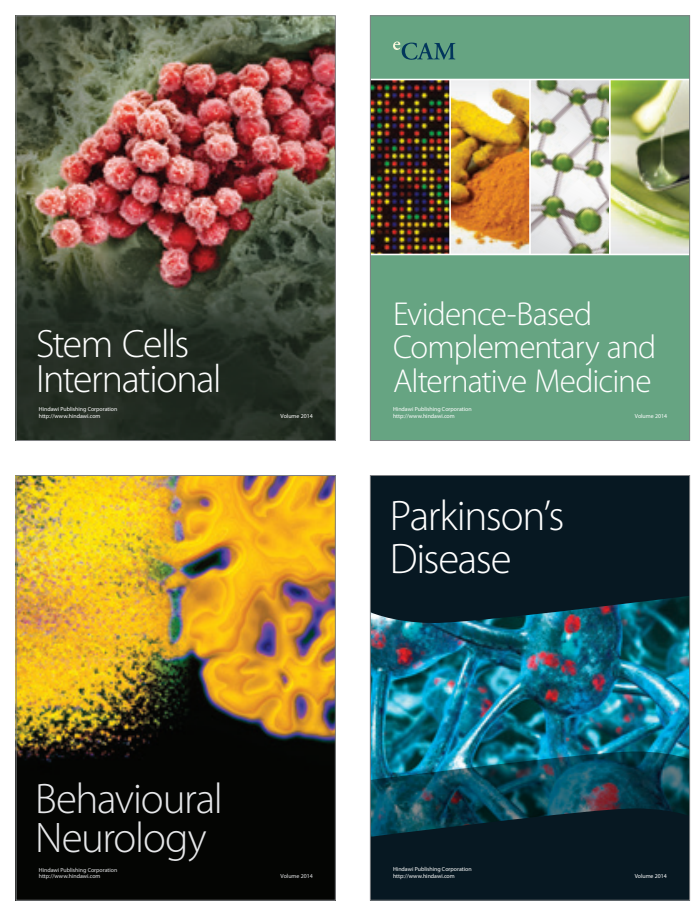

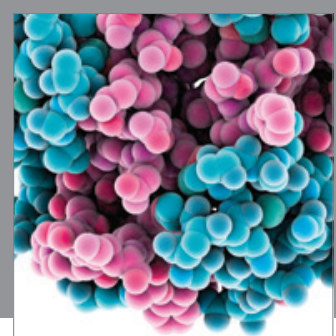

Journal of
Diabetes Research

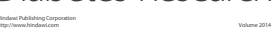

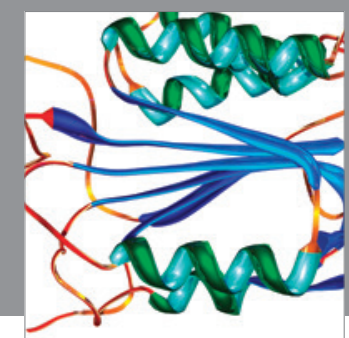

Disease Markers
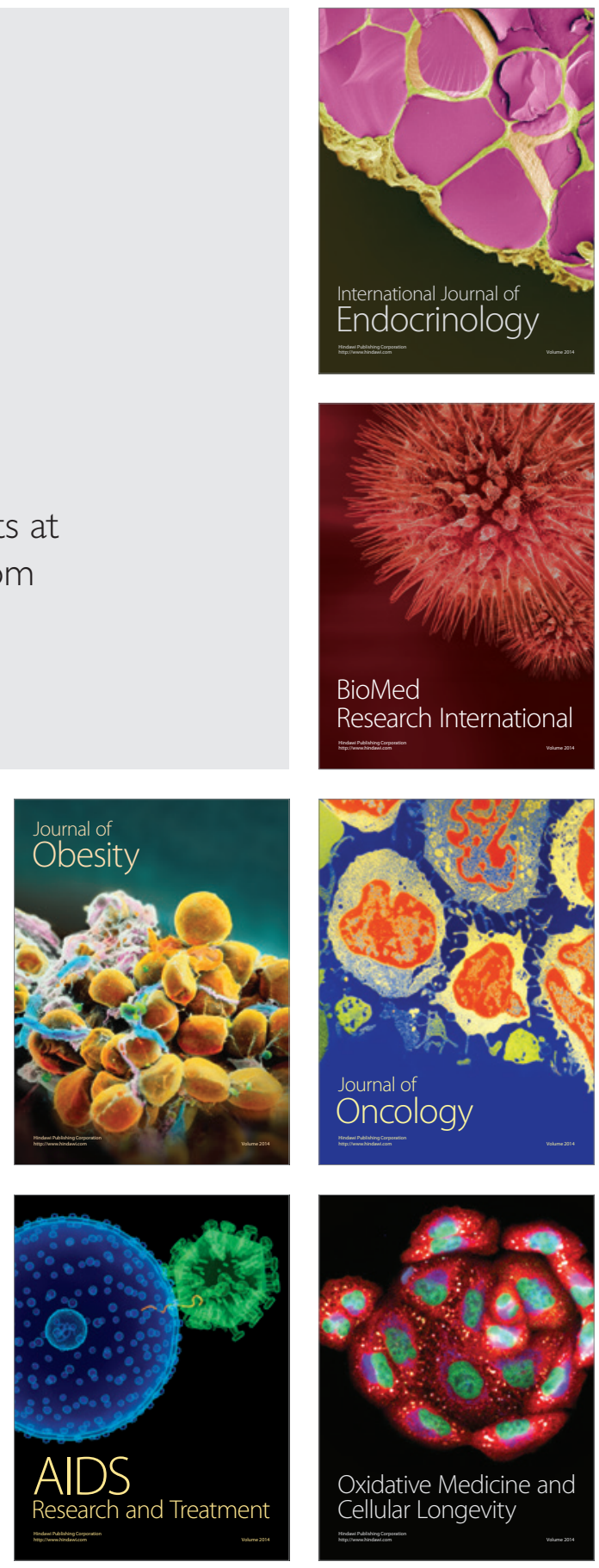